\title{
Elevated circulating high-sensitivity cardiac troponin $t$ and cardiac remodeling in obesity
}

Jiaojiao Huang ${ }^{1 \dagger}$, Ming $\mathrm{Liu}^{2 \dagger}$, Enyong Su${ }^{3}$, Peng Yu ${ }^{4 *}$, Hong Jiang ${ }^{3 *}$, Ji Zhao ${ }^{3}$ and Junbo Ge ${ }^{3}$

\begin{abstract}
Background: It is well established that body mass index (BMI) and troponins are independently associated. However, whether the obesity could cause myocardial injury independent of coronary heart disease (CHD) remains unclear. This study focuses on the relationship between BMI and troponins, and whether this relationship is being attenuated when $\mathrm{CHD}$ is accounted for.

Methods: In populations without acute ischemic events, 383 patients with coronary artery stenosis less than $75 \%$ were included, that is, people who have not yet reached the indications for coronary intervention, and of them 70 patients being obese according to $\mathrm{BMI} \geq 28 \mathrm{~kg} / \mathrm{m}^{2}$. Continuous variables were represented as mean $\pm \mathrm{SD}$ or median(inter quartile range[IQR]). Chi-square test was adopted for categorical data. Correlations between variables were evaluated by Spearman analysis, multiple regression or logistic regression.

Results: The circulating hs-cTnT level was higher in the obese group $[8(6,11) \mathrm{ng} / \mathrm{L} \mathrm{vs}$. $6(4,9) \mathrm{ng} / \mathrm{L} ; p<0.001)$. In subgroup analysis based on the presence or absence of coronary heart disease(CHD), the adjusted $\beta(95 \% \mathrm{Cl})$ for circulating hs-cTnT exhibited a proportional relationship with BMI when the non-obesity were defined as the reference[ $\beta$; $2.22(95 \% \mathrm{Cl}, 0.73$ to 3.71$)$ in non-CHD, $5.58(95 \% \mathrm{Cl}, 0.70$ to 10.46$)$ in $\mathrm{CHD}, p<0.05]$. Additionally, the degree of coronary stenosis has shown a positive correlation with circulating hs-cTnT ( $r h o=0.1162 ; p<0.05)$.

Conclusion: When CHD is taken into account, obesity is independently associated to the elevation of circulating hs-cTnT, a biomarker of myocardial injury, potentially indicating the impact of obesity on non-ischemic subclinical myocardial injury.
\end{abstract}

Keywords: Obesity, High-sensitivity cardiac troponin T, Myocardial injury, Coronary heart disease

\section{Introduction}

Obese men and obese women respectively account for $16.3 \%$ and $12.4 \%$ globally, and maintain a steady growth trend. Admittedly, obesity is closely associated with the development and occurrence of cardiovascular disease

\footnotetext{
*Correspondence: 15111210028@fudan.edu.cn; jianghong_@fudan.edu.cn

${ }^{\dagger}$ Jiaojiao Huang and Ming Liu These authors contributed equally to this paper

${ }^{3}$ Shanghai Institute of Cardiovascular Diseases, Shanghai Institute

of Clinical Bioinformatics, Zhongshan Hospital, Shanghai Medical College

of Fudan University, Shanghai, China

${ }^{4}$ Department of Endocrinology and Metabolism, Zhongshan Hospital,

Shanghai Medical College of Fudan University, Shanghai, China

Full list of author information is available at the end of the article
}

(CVD) $[1,2]$ including: cardiac artery disease (CAD) and non-ischemic heart disease. Meanwhile, obesity may often accompany with myocardial injury, which indicates a worse prognosis for CVD.

Myocardial injury may be led by two factors. On the one hand, the CAD including stable angina pectoris and acute coronary syndrome (ACS) could cause damage to myocardium due to myocardial ischemia [3]. On the other hand, myocardial injury would inevitably come with the non-ischemic heart disease such as cardiac remodeling or dysfunction diseases. Current studies $[4,5]$ show that obesity is independently associated with cardiac remodeling, with left ventricular structural abnormalities-related indicators having a dose-response 
relationship with body mass index (BMI). Meanwhile, obesity is a culprit behind the occurrence of heart failure (HF), manifested by diastolic HF and subsequent systolic HF [6]. However, to our best knowledge, few studies directly explore the relationship between obesity and subclinical myocardial injury, taking coronary artery diseases into account. A study based on National Health and Nutrition Examination Survey (NHASNES) III suggested that obesity is positively associated with subclinical myocardial injury [7]. But what is more noteworthy is that there are virtually no studies excluding the effects of coronary vascular lesions on myocardial injury through the gold standard coronary angiography to prove the correlation between obesity and myocardial injury. Additionally, circulating cardiac Troponin $\mathrm{T}$ (cTnT) especially for circulating high-sensitivity cardiac Troponin $\mathrm{T}$ (hs$\mathrm{c} \operatorname{Tn} \mathrm{T})$, an extensively acknowledged biomarker for myocardial injury in today's clinical settings, routinely serves as a diagnostic tool for ACS when it exceeds the 99th percentile of the upper limit of the refence value at least once [8]. Meanwhile, its slight elevation might suggest the minor damage on cardiac muscle. And with time, the elevation in circulating hs-cTnT would have a predictive effect on the occurrence of events and a higher mortality risk $[9,10]$.

The aim of this cross-sectional study was to find whether there existed an independent correlation between obesity and slightly elevated circulating hs-cTnT under the premise of excluding the influence of CHD, which may be the evidence on non-ischemic subclinical myocardial injury caused by obesity.

\section{Methods}

\section{Study population}

Patients who underwent coronary angiography due to long-term chronic chest discomfort at Zhongshan Hospital ranging from December 1st, 2020 to May 30th, 2021 at Fudan University were screened in the study. Patients with coronary artery stenosis less than $75 \%$, that is, noncoronary heart disease (non-CHD) patients (coronary artery stenosis less than 50\%) and coronary heart disease patients who did not meet the indications for intervention (coronary artery stenosis less than $75 \%$ but more than or equal to 50\%) were consecutively enrolled. Exclusion criteria were as follows [11]: incomplete clinical data, acute myocardial ischemic event (ACS on admission), a history of cardiovascular events (including stroke, ACS or HF), structural cardiomyopathy, atrial fibrillation or flutter, atrioventricular block and tachycardia, implanted pacemakers, sepsis, bronchial or lung disease, hyperthyroidism and end-stage renal disease. The calculation of sample sizes was based on previous literature [12], of which the circulating hs-cTnT stood at $2.3(1.5,3.7)$ $\mathrm{pg} / \mathrm{ml}$ (equal to $\mathrm{ng} / \mathrm{L}$ ), in the non-metabolic syndrome group and 3.4 $(2.2,4.6) \mathrm{pg} / \mathrm{ml}$ in the metabolic syndrome group, and the tool [13] https://www.math.hkbu.edu.hk/ $\sim$ tongt/papers/median2mean.html was used in order to transform the data into mean $\pm \mathrm{SD}$, respectively being $2.51 \pm 1.63 \mathrm{pg} / \mathrm{ml}$ and $3.40 \pm 1.80 \mathrm{pg} / \mathrm{ml}$ after the transformation. Then we input the syntax to the STATA, namely sampsi 2.513 .4 , sd1 (1.63) sd2 (1.8) power (0.80) alpha (0.05) ratio (4). The results were $\mathrm{n}_{1}=35$ and $\mathrm{n}_{2}=140$. The number of enrolled patients was twice as much as the minimum requirement.

The study was approved by the Ethical Committee of Zhongshan Hospital, Fudan University, China and all participants had signed informed consent, which was in line with the principles declared in the 1975 Declaration of Helsinki.

\section{Data collection}

We retrospectively collected data on demographic characteristics, symptoms and signs, previous combined diseases, coronary angiography and Doppler ultrasound results. All blood samples were obtained on the first morning of hospitalization after an overnight fast for laboratory measurements. Laboratory data of peripheral venous blood including blood cell counts, inflammation indicators, cardiac function, hepatic function, renal function, thyroid function, lipids and sugar levels are recorded. All results were checked by another researcher.

The blood pressure (BP) of patients was measured repeatedly three times at an interval of two minutes in the morning by Omron electric sphygmomanometer (U30; Omron Dalian Co., Ltd; Dalian; China) and we record the average value. Hypertension was defined as those with mean systolic blood pressure (SBP) $\geq 140 \mathrm{mmHg}$ and/or mean diastolic blood pressure $(\mathrm{DBP}) \geq 90 \mathrm{mmHg}$ or taking antihypertensive drugs. Diabetes mellitus was characterized as hemoglobin A1c $(\mathrm{HbA1c}) \geq 6.5 \%$, fasting blood glucose (FBG) $\geq 7.0 \mathrm{mmol} / \mathrm{L}, 2$-h plasma glucose $\geq 11.1 \mathrm{mmol} / \mathrm{L}$, a random plasma glucose $\geq 11.1 \mathrm{mmol} / \mathrm{L}$ or receiving hypoglycemic treatments. Individuals with high-density lipoprotein cholesterol (HDL-C) $\leq 40 \mathrm{mg} / \mathrm{dL}$, low-density lipoprotein cholesterol (LDL-C) $\geq 140 \mathrm{mg} / \mathrm{dL}$, triglycerides $\geq 150 \mathrm{mg} / \mathrm{dL}$ or taking lipid-lowering medications were listed as hyperlipidemia. Body mass index (BMI) refers to the weight in kilograms divided by the square of the height in meters. Obesity was defined as BMI $\geq 28 \mathrm{~kg} /$ $\mathrm{m}^{2}$ [14].

\section{Biochemical measurements}

The level of circulating hs-cTnT is obtained using a high-sensitivity and high-precision cardiac troponin assay-Troponin T hs STAT (Roche Diagnostics GmbH 
Shanghai Co., Ltd, Shanghai, China) by electrochemiluminescence in the Cobas e601(Roche Diagnostics GmbH Shanghai Co., Ltd, Shanghai, China). Circulating hscTnT's normal reference value range stands at $0-14 \mathrm{ng} / \mathrm{L}$, with its lower limit of detection being $3 \mathrm{ng} / \mathrm{L}$ [9].

\section{Echocardiographic measurement}

Echocardiograms were measured using the EPIQ 7C Ultrasound System (Phillips Medical Systems, Bothell, Washington) with a 1.0- to $5.0-\mathrm{MHz}$ transducer based on the recommendation of the American Society of Echocardiography [15]. All patients were recommended to lie in a left lateral recumbent position. In the parasternal long and short axes and the apical 4- and 2- chamber long-axis perspective, two-dimensional and Doppler images were recorded. From the parasternal perspective, M-mode echocardiograms of the left ventricle (LV) were obtained. All records averaged at least 3 cardiac cycles and were digitally stored for subsequent statistical analysis. Left ventricular end-systolic diameter (LVESD), left ventricular end-diastolic diameter (LVEDD), posterior wall thickness (PWT) and interventricular septal thickness (IVST) were measured using M-mode or 2-dimensional echocardiography from the parasternal long axis view. Left atrial dimension (LAD) were measured in 3 orthogonal planes: the parasternal long, lateral and super-inferior axes. Left ventricular ejection (LVEF) was calculated from LV end-systolic and end-diastolic volumes (LVESV and LVEDV) estimated from the apical 4- and 2- chambers perspectives by Simpson biplane method. The deceleration time (DT) of early diastolic velocity were recorded as indicators of LV end-diastolic pressure.

\section{Statistical analysis}

All continuous variables were tested for normality using Kolmogorov-Smirnov test. If being normal distribution, the data were represented as mean $\pm \mathrm{SD}$ and compared by the Student's test. Otherwise, the data were reported as median (inter quartile range [IQR]) and the MannWhitney U-test. Chi-square test is adopted for categorical data. Correlation between obesity and circulating hs-cTnT was evaluated by multiple linear regression, with hs-cTnT serving as the dependent variable. For association between parameters in echocardiography and circulating hs-cTnT or BMI, spearman correlation analysis was practiced. $P$ value $<0.05$ was considered statistically significant. Stata 12 for windows (Stata-Corp, College Station, TX, USA) was used during the statistical analysis process.

\section{Results}

\section{Demographical and clinical characteristics}

A total of 383 patients with coronary artery stenosis less than $75 \%$ were included in the study. Of them, $313(81.7 \%)$ were non-obese and the remaining 70 (19.3\%) individuals were obese. The mean age was $61.6 \pm 0.5$ years and male patients stood at 218 (56.9\%). Demographical and clinical characteristics of the participants were shown in Table 1 . The obesity group tended to have more unfavorable metabolic profiles, namely, the obese had higher SBP, DBP and HbA1c than their counterparts. However, the obese showed lower HDL-c compared with the non-obese. Notably, circulating hs-cTnT were apparently higher in obese group than non-obese group. Besides, alanine transaminase (ALT) and C-reactive protein (CRP) were higher in obesity group. Other factors such as D-dimer, isoenzyme of creatine kinase (CK-MB), aspartate transaminase (AST), glomerular filtration rate (GFR), creatinine, total cholesterol (TC), total triglycerides (TG), LDL-c and thyrotropin-releasing hormone (TSH) did not show statistical differences.

\section{Parameters in echocardiography between obesity and non-obesity}

In comparison with the non-obesity group, the obesity group had higher echocardiography's parameters, with atrioventricular enlargement and wall thickening as main manifestations. More specifically, obese individuals showed higher values of indicators representing cardiac hypertrophy such as LAD, LVEDD, LVEDS, IVST and PWT in Table 2. However, no significant difference in cardiac systolic or diastolic function was observed.

\section{Independent correlation between BMI and circulating hs-cTnT}

As shown in Table 3 , the adjusted $\beta(95 \% \mathrm{CI})$ for circulating hs-cTnT exhibited a proportional relationship with BMI in subgroup analysis based on the presence or absence of coronary heart disease (CHD). Multiple linear regression was adopted with the non-obese being defined as the reference. Both in non-CHD and CHD group, $\beta(95 \% \mathrm{CI})$ values for circulating hs-cTnT exhibited a proportional relationship with BMI regardless of whether possible confounders were adjusted. In unadjusted model, $\beta$ values in non-CHD and CHD respectively were 2.89 (95\%CI, 1.43 to 4.36 ) and 5.64 (95\%CI, 1.78 to 9.5 ). In order to ensure the credibility of the research results, we have adjusted the known confounding factors. When age and sex were adjusted, $\beta$ values in non-CHD and CHD respectively stood at 2.80 (95\%CI, 1.43 to 4.16 ) and 6.62 (95\%CI, 2.63 to 10.62). Additional adjustment for DM, HBP, hyperlipidemia, systolic BP, diastolic BP, 
Table 1 Clinical characteristic of 383 patients

\begin{tabular}{|c|c|c|c|c|}
\hline & \multicolumn{2}{|l|}{ BMI } & \multirow[t]{2}{*}{$t / z /$ value } & \multirow[t]{2}{*}{$P$ value } \\
\hline & Non-obesity $(n=313)$ & Obesity $(n=70)$ & & \\
\hline Age (years old, $\bar{x} \pm s$ ) & $61.91 \pm 9.33$ & $59.80 \pm 9.36$ & 1.71 & 0.09 \\
\hline Male (number, \%) & $177(56.55)$ & $41(58.57)$ & $0.10^{\mathrm{a}}$ & 0.76 \\
\hline Height $(\mathrm{cm}, \bar{x} \pm s)$ & $165.45 \pm 7.79$ & $164.67 \pm 9.39$ & 0.64 & 0.52 \\
\hline Weight (kg, $\bar{x} \pm s)$ & $66.52 \pm 9.68$ & $82.36 \pm 9.80$ & -12.34 & $<0.001^{*}$ \\
\hline Systolic BP (mmHg, $\bar{x} \pm s)$ & $129.89 \pm 18.33$ & $135.46 \pm 18.25$ & -2.3 & $0.02^{*}$ \\
\hline Diastolic BP (mmHg, $\bar{x} \pm s)$ & $79.02 \pm 10.86$ & $82.33 \pm 9.23$ & -2.36 & $0.02^{*}$ \\
\hline DM (number, \%) & $56(17.89)$ & $14(20.00)$ & $0.17^{\mathrm{a}}$ & 0.68 \\
\hline HBP (number, \%) & $29(15.68)$ & $41(20.71)$ & $1.62^{\mathrm{a}}$ & 0.2 \\
\hline Coronary stenosis $\left[\%, M\left(\mathrm{Q}_{1}, \mathrm{Q}_{3}\right)\right]$ & $30(0,50)$ & $30(0,40)$ & $1.52^{\mathrm{b}}$ & 0.13 \\
\hline Hyperlipidemia (number, \%) & $31(9.90)$ & $6(8.57)$ & $0.12^{\mathrm{a}}$ & 0.73 \\
\hline hs-cTnT(ng/L, $\bar{x} \pm s)$ & $6(4,9)$ & $8(6,11)$ & $-3.69^{b}$ & $<0.001^{*}$ \\
\hline NT-pro BNP $\left[\mathrm{pg} / \mathrm{ml}, \mathrm{M}\left(\mathrm{Q}_{1}, \mathrm{Q}_{3}\right)\right]$ & $48.8(25.4,104)$ & $37.05(14.60,71.30)$ & $2.35^{\mathrm{b}}$ & $0.02^{*}$ \\
\hline CK-MB[U/L,M(Q $\left.\left(Q_{1}, Q_{3}\right)\right]$ & $15(13,19)$ & $16(13,19)$ & $-1.37^{b}$ & 0.17 \\
\hline $\mathrm{CRP}\left[\mathrm{mg} / \mathrm{L}, \mathrm{M}\left(\mathrm{Q}_{1}, \mathrm{Q}_{3}\right)\right]$ & $0.90(0.40,2.15)$ & $1.25(0.70,3.00)$ & $-2.30^{\mathrm{b}}$ & $0.02^{*}$ \\
\hline $\mathrm{D}-\operatorname{dimer}\left[\mathrm{mg} / \mathrm{L}, \mathrm{M}\left(\mathrm{Q}_{1}, \mathrm{Q}_{3}\right)\right]$ & $0.19(0.19,0.29)$ & $0.19(0.19,0.25)$ & $0.66^{\mathrm{b}}$ & 0.51 \\
\hline $\operatorname{ALT}\left[U / L, M\left(Q_{1}, Q_{3}\right)\right]$ & $18(14,26)$ & $23(17,33)$ & $-2.75^{b}$ & $0.01^{*}$ \\
\hline AST $\left[U / L, M\left(Q_{1}, Q_{3}\right)\right]$ & $19(16,23)$ & $19(16,24)$ & $-0.64^{b}$ & 0.52 \\
\hline $\mathrm{GFR}\left(\mathrm{ml} / \mathrm{min} / 1.73 \mathrm{~m}^{2}, \overline{\mathrm{x}} \pm \mathrm{s}\right.$ & $76.07 \pm 17.57$ & $78.24 \pm 16.80$ & -0.94 & 0.35 \\
\hline Creatinine $\left[\mu \mathrm{mol} / \mathrm{L}, \mathrm{M}\left(\mathrm{Q}_{1}, \mathrm{Q}_{3}\right)\right]$ & $73(61,84)$ & $74(62,85)$ & $0.31^{\mathrm{b}}$ & 0.76 \\
\hline Glucose[mmol/L,M(Q $\left.\left.\mathrm{Q}_{1}, \mathrm{Q}_{3}\right)\right]$ & $5.7(5.1,7.3)$ & $5.8(5.1,6.8)$ & $0.06^{\mathrm{b}}$ & 0.95 \\
\hline Glycated albumin(\%,, $\pm s)$ & $14.66 \pm 2.94$ & $14.70 \pm 3.68$ & -0.11 & 0.91 \\
\hline $\mathrm{HbA}{ }_{1} c\left[\%, M\left(Q_{1}, Q_{3}\right)\right]$ & $5.7(5.4,6.1)$ & $5.8(5.6,6.4)$ & $-2.20^{b}$ & $0.03^{*}$ \\
\hline $\mathrm{TC}(\mathrm{mmol} / \mathrm{L}, \overline{\mathrm{x}} \pm s)$ & $4.02 \pm 1.11$ & $4.08 \pm 1.05$ & -0.39 & 0.7 \\
\hline $\mathrm{TG}(\mathrm{mmol} / \mathrm{L}, \bar{x} \pm s)$ & $1.71 \pm 1.17$ & $1.85 \pm 1.07$ & -0.96 & 0.34 \\
\hline $\mathrm{HDL}-\mathrm{c}(\mathrm{mmol} / \mathrm{L}, \bar{x} \pm s)$ & $1.22 \pm 0.32$ & $1.13 \pm 0.28$ & 2.41 & $0.02^{*}$ \\
\hline $\mathrm{LDL}-\mathrm{c}(\mathrm{mmol} / \mathrm{L}, \bar{x} \pm s)$ & $2.06 \pm 0.86$ & $2.18 \pm 0.89$ & -1.02 & 0.31 \\
\hline $\mathrm{TSH}(\mu \mathrm{lU} / \mathrm{ml}, \overline{\mathrm{x}} \pm \mathrm{s})$ & $2.16 \pm 1.59$ & $1.94 \pm 1.42$ & 1.09 & 0.27 \\
\hline
\end{tabular}

$a, x^{2}$ value; $b$, z value; $B M I$, body mass index; $B P$, blood pressure; DM, diabetes mellitus; HBP, high blood pressure; hs-cTnT, high sensitivity cardiac troponin; NT-pro BNP, brain natriuretic peptid; CK-MB, isoenzyme of creatine kinase; CRP, C-reactive protein; ALT, alanine transaminase; AST, aspartate transaminase; GFR, glomerular filtration rate; $\mathrm{HbA}_{1} \mathrm{C}$, glycated hemoglobin; $\mathrm{TC}$, total cholesterol; $\mathrm{TG}$, total triglycerides; $\mathrm{HDL}$-c, high-density lipoprotein cholesterol; $\mathrm{LDL}$-c, low-density lipoprotein cholesterol; $\mathrm{TSH}$, thyrotropin-releasing hormone

* $p<0.05$

CK-MB, NT-pro BNP, CRP, D-dimmer, ALT, AST, GFR, creatinine, glucose, glycated albumin, HbA1c, TC, TG, HDL-c, LDL-c and TSH led to a slight attenuation of the $\beta$ values both in non-CHD and CHD, respectively standing at $2.22(95 \% \mathrm{CI}, 0.73$ to 3.71$)$ and $5.58(95 \% \mathrm{CI}, 0.70$ to 10.46).

\section{Spearman correlation analysis showed a significant relationship between $\mathrm{BMI}$ and cardiac remodeling}

The association between BMI and parameters in echocardiography or NT-pro BNP is exhibited in Table 4. BMI has shown an apparently positive correlation with LAD, LVEDD, LVEDS, IVST, PWT and NT-pro-BNP $($ rho $=0.4985,0.3723,0.3698,0.3852,0.3533$ and -0.17 ; all $p<0.001)$ in spearman correlation analysis, potentially suggesting that obesity may be accompanied by cell enlargement and hypertrophy. However, BMI had no association with ventricular systolic or diastolic function.

\section{Spearman correlation analysis showed a significant relationship between cardiac remodeling and circulating hs-cTnT}

The Rho for the association between parameters in echocardiography or NT-pro BNP and circulating hs-cTnT was displayed in Table 5. There existed a significantly positive correlation between circulating hs-cTnT and LAD, LVEDD, LVEDS, IVST, PWT and NT-pro-BNP $($ rho $=0.2705,0.1300,0.1378,0.2256,0.1742$ and 0.1049 ; all $p<0.05)$ in spearman correlation analysis, potentially indicating a significant relationship between cardiac 
Table 2 Parameters in echocardiography in 383 patients

\begin{tabular}{|c|c|c|c|c|}
\hline & \multicolumn{2}{|l|}{ BMI } & \multirow[t]{2}{*}{ t value } & \multirow[t]{2}{*}{$p$ value } \\
\hline & Non-obesity $(n=313)$ & Obesity $(n=70)$ & & \\
\hline $\mathrm{AAO}(\mathrm{mm}, \overline{\mathrm{x}} \pm \mathrm{s})$ & $1.51 \pm 0.04$ & $1.52 \pm 0.04$ & -0.98 & 0.33 \\
\hline $\operatorname{LAD}(m m, \bar{x} \pm s)$ & $37.48 \pm 3.78$ & $40.83 \pm 3.49$ & -6.58 & $<0.001^{*}$ \\
\hline $\operatorname{LVEDD}(m m, \bar{x} \pm s)$ & $45.80 \pm 3.69$ & $48.30 \pm 4.04$ & -4.87 & $<0.001^{*}$ \\
\hline $\operatorname{LVEDS}(m m, \bar{x} \pm s)$ & $29.22 \pm 2.63$ & $31.05 \pm 3.09$ & -4.91 & $<0.001^{*}$ \\
\hline IVST(mm, $\bar{x} \pm s)$ & $9.53 \pm 1.26$ & $10.15 \pm 1.06$ & -3.71 & $<0.001^{*}$ \\
\hline PWT(mm, $\bar{x} \pm s)$ & $9.08 \pm 1.01$ & $9.58 \pm 0.88$ & -3.64 & $<0.001^{*}$ \\
\hline $\operatorname{PASP}(m m H g, \bar{x} \pm s)$ & $31.55 \pm 3.92$ & $32.02 \pm 3.04$ & -0.90 & 0.37 \\
\hline $\mathrm{DT}(\mathrm{ms}, \overline{\mathrm{x}} \pm \mathrm{s})$ & $181.75 \pm 28.76$ & $185.57 \pm 31.83$ & -0.95 & 0.34 \\
\hline $\operatorname{LVEF}(\%, \bar{x} \pm s)$ & $65.51 \pm 3.38$ & $64.85 \pm 4.08$ & 1.22 & 0.23 \\
\hline
\end{tabular}

AAO, aortic root angiogram; LAD, left atrial dimension; LVEDD, left ventricular end-diastolic dimension; LVEDS, left ventricular end-systolic dimension; IVST, interventricular septal thickness; PWT, posterior wall thickness; PASP, pulmonary artery systolic pressure; DT, e peak deceleration time; LVEF, left ventricular ejection fraction

${ }^{*} p<0.05$

Table $3 \beta$ value of hs-cTnT in the study group according to BMI

\begin{tabular}{llll}
\hline $\begin{array}{l}\text { Degree of } \\
\text { coronary } \\
\text { stenosis }\end{array}$ & $\begin{array}{l}\text { Model 1 } \\
\boldsymbol{\beta ( 9 5 \% C l )}\end{array}$ & $\begin{array}{l}\text { Model 2 } \\
\boldsymbol{\beta}(\mathbf{9 5 \%} \mathbf{C l})\end{array}$ & $\begin{array}{l}\text { Model 3 } \\
\boldsymbol{\beta}(\mathbf{9 5 \%} \% \mathbf{C l})\end{array}$ \\
\hline$[0,50 \%)$ & & & \\
non-obesity & Reference & Reference & Reference \\
$\begin{array}{l}\text { Obesity } \\
{[50 \%, 75 \%)}\end{array}$ & $2.89(1.43,4.36)$ & $2.80(1.43,4.16)$ & $2.22(0.73,3.71)$ \\
non-obesity & Reference & Reference & Reference \\
Obesity & $5.64(1.78,9.50)$ & $6.62(2.63,10.62)$ & $5.58(0.70,10.46)$ \\
\hline
\end{tabular}

$\mathrm{Cl}$, confidential interval

Model 1: unadjusted

Model 2: adjusted for age and sex

Model 3: adjusted for age, sex, DM, HBP, hyperlipidemia, systolic BP, diastolic BP, CK-MB, NT-pro BNP, CRP, D-dimer, ALT, AST, GFR, creatinine, glucose, glycated albumin, HbA1c, TC, TG, HDL-c, LDL-c and TSH

hypertrophy and circulating hs-cTnT. However, circulating hs-cTnT had no association with cardiac systolic or diastolic function, which showed the subclinical myocardial injury caused by obesity is earlier than abnormal cardiac function.

\section{Hs-cTnT differed between non-obesity and obesity groups and correlated with BMI}

The level of circulating hs-cTnT in obesity group was significantly higher than its counterpart in Fig. 1a. Meanwhile, BMI had shown a positive correlation with circulating hs-cTnT, with its rho standing at 0.209 $(p<0.001)$ in Fig. 1b.

\section{Discussion}

The number of individuals with myocardial injury is steadily growing worldwide. Obese individuals are at high risk of myocardial injury than their non-obese counterparts. At the same time, considering that few studies involve the correlation between obesity and subclinical myocardial injury after excluding the impact of CHD, necessitating the emergence of our research. Briefly, our

Table 4 Association between BMI and parameters in echocardiography or NT-pro BNP

\begin{tabular}{|c|c|c|c|c|c|c|c|c|c|c|}
\hline & AAO & LAD & LVEDD & LVEDS & IVST & PWT & DT & PASP & LVEF & NTpro-BNP \\
\hline Rho & 0.1809 & 0.4985 & 0.3723 & 0.3698 & 0.3852 & 0.3533 & 0.0604 & -0.0492 & -0.0794 & -0.17 \\
\hline$p$ value & $<0.001^{*}$ & $<0.001^{*}$ & $<0.001^{*}$ & $<0.001^{*}$ & $<0.001^{*}$ & $<0.001^{*}$ & 0.2597 & 0.3540 & 0.1344 & $<0.001^{*}$ \\
\hline
\end{tabular}

${ }^{*} p<0.05$

Table 5 Association between parameters in echocardiography or NT-pro BNP and hs-cTnT

\begin{tabular}{|c|c|c|c|c|c|c|c|c|c|c|}
\hline & AAO & LAD & LVEDD & LVEDS & IVST & PWT & DT & PASP & LVEF & NTpro-BNP \\
\hline Rho & 0.2469 & 0.2705 & 0.1300 & 0.1378 & 0.2256 & 0.1742 & 0.0109 & 0.0455 & -0.0297 & 0.1049 \\
\hline$p$ value & $<0.001^{*}$ & $<0.001^{*}$ & $<0.05^{*}$ & $<0.05^{*}$ & $<0.001^{*}$ & $<0.001^{*}$ & 0.8394 & 0.3913 & 0.5758 & $<0.05^{*}$ \\
\hline
\end{tabular}

${ }^{*} p<0.05$ 
A

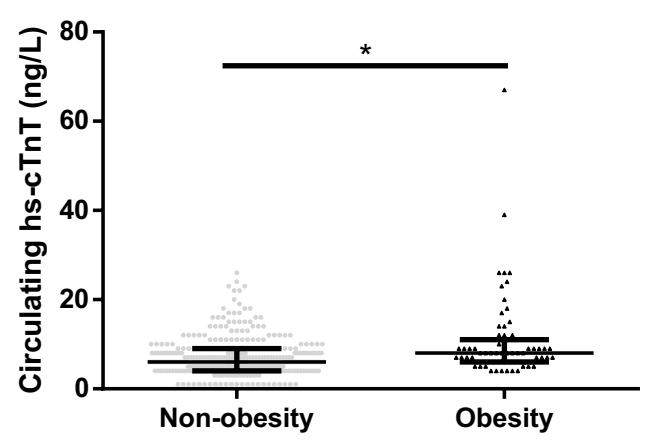

B

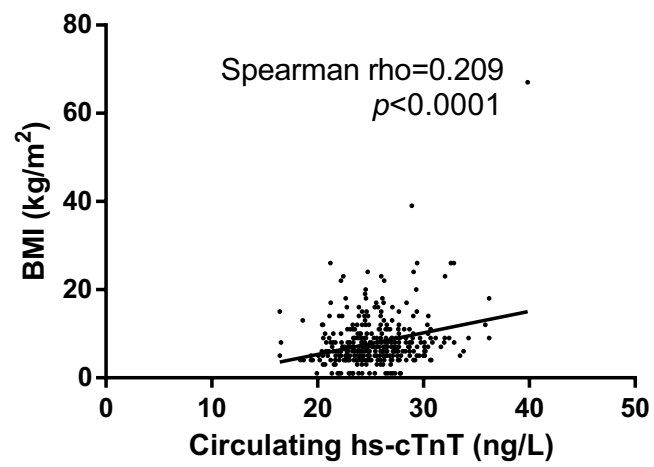

Fig. $1 \mathrm{Hs}$-cTnT differs between groups and correlates with BMI. Circulating hs-cTnT levels in the two groups, shown in Median, IQR (A). Correlation between circulating hs-cTnT and BMI (B). ${ }^{*} p<0.05$

research had the following major findings on the premise of excluding the impact of other possible confounding factors: (i) There exists differences in circulating hs-cTnT, echocardiographic indexes and the inflammatory marker CRP between the obese group and the non-obese group, but no difference is displayed in the degree of coronary stenosis. (ii) Compared with the non-obese, BMI is independently associated with elevated but still within the normal range of circulating hs-cTnT independent of the degree of coronary stenosis; BMI is linked with early cardiac remodeling. (iii) Before cardiac diastolic and systolic function are affected, there is a certain correlation between slightly elevated circulating hs-cTnT and early cardiac remodeling.

Our findings are in an accordance with some community-based studies which explored the association between BMI and circulating hs-cTnT in continuous and categorical analyses. The ARIC (Atherosclerosis Risk in Communities) study [16] recruited 9,507 participants without baseline CAD to assess the association between BMI and circulating hs-cTnT in cross-sectional stage. In categorical analysis, the authors demonstrated that higher BMI groups were linked with a heightened probability of high circulating hs-cTnT levels ( $\geq 14 \mathrm{ng} / \mathrm{L})$ even after all possible risk factors were adjusted. In continuous analysis, an independent, linear relationship between BMI and high circulating hs-cTnT levels were finalized when BMI was modeled continuously using a restricted cubic spline. In our study with all known confounders especially the presence of CHD being taken into account, we found that obesity remained independently related to subclinical myocardial injury. Of note, we conducted a stratified analysis of the degree of coronary stenosis and the correlation remained robust, thus providing confirmatory results for the study. In this regard, we believe that more attention should be given to non-ischemic subclinical myocardial injury related to obesity.

Indeed, the role of obesity in cardiovascular disease (CVD) is achieved through mechanisms such as inflammation, oxidative stress, fibrosis and alteration in cardiac function [17-21]. Meanwhile, numerous studies have revealed the potential role of adipose tissue (AT) inflammation to obesity-linked insulin resistance [22, 23]. Assessing the association between circulating hs-cTnT and CRP was beyond the present study's reach. However, we speculated that the difference in systematic inflammation between the obese and the non-obese may be one of the pathological mechanisms leading to subclinical injury. Previous animal studies have suggested that obesity and obesity-linked insulin resistance threaten to paralyze mitochondrial function and fatty acids, causing elevated oxidative stress, release of inflammatory cytokines such as tumor necrosis- $\alpha$ (TNF- $\alpha$ ) and interleukin-6 (IL-6) and an imbalance in adipokines [24-26]. These disorders are responsible for asymptomatic myocardial injury in obesity.

Persistent increase in troponin would further cause clinical cardiac remodeling [27]. We demonstrated that circulating hs-cTnT was associated with early cardiac remodeling before systolic and diastolic functions of the heart being not affected. Unanimously, Ravassa and Kuznetsova et al. [28] found that subclinical LV and LA remodeling was related to myocardial injury, with alternation in circulating hs-cTnT being the main manifestation. Additionally, our study also found that BMI is associated with early cardiac remodeling. Admittedly, cardiac remodeling is deemed as a preclinical form of HF that predisposes to subsequent HF. An animal model $[29,30]$ using cTnT as an inducer of immune myocarditis could be sufficient to explain why obese individuals with a seemingly healthy heart could progress into overt HF. 
The continuous presence of circulating hs-cTnT induces the sustained release of cardiomyocytes' local inflammation, followed by cardiomegaly, fibrosis, reduced cardiac functions and 30\% mortality over 270 days. In published population-based studies [31-33], the correlation between obesity and late cardiac remodeling or even HF has been verified and reached a conclusion. A crosssectional study based in South Korea found that the increased BMI was closely associated with both structural and functional left ventricular (LV) abnormalities [34]. The Framingham Heart Study showed that obese subjects had a doubling of the risk of HF compared with subjects with a normal BMI after a 14-year-long followup [32].

Circulating cardiac troponin levels are routinely used as a diagnostic tool for ACS but also served as differentiating myocardial injury from CHD [8]. Certainly, the efficacy of circulating cardiac troponin as forecasters of cardiovascular events in non-ischemic heart disease has been testified. A mild increase in circulating cardiac troponin has been a sign of myocardial injury and is associated with future CHD events, which was testified by a recent study. $[9,10]$ Thus, assessment of myocardial injury among obese individuals appears to be significantly important since a mild increase in circulating cardiac troponin within the normal range has shown a relationship with future cardiovascular events. We concentrated on circulating hs-cTnT to detect subclinical myocardial injury when exploring the association between obesity and circulating hs-cTnT. Thus, findings from our study indicate that it is necessary for obese individuals to carry out regular screening of myocardial injury markers to avoid potentially subsequent cardiovascular events.

The innovation of this study lies in the fact that we finalized that obesity is related to slightly elevated troponin independent of CHD, implying a brand-new viewpoint that non-ischemic myocardial injury is accompanied by obesity although people has not evolved into HF. Most importantly, our discovery makes the chain of HF's development and occurrence appear to be more complete, potentially deepening people's understanding of HF.

\section{Conclusions}

To sum up, our study has confirmed (that) the contribution of obesity to the slightly elevated circulating hs-cTnT when CHD is accounted for, which potentially indicates the independent impact of obesity on non-ischemic subclinical myocardial injury. And efforts to promote optimal body weight may reduce the risk of non-ischemic subclinical myocardial injury. Management of risk factors for subclinical myocardial injury and preclinical phases of HF should be prioritized considering the alarming trend toward growing obese population globally.

\section{Limitations}

Our study serving as a cross-sectional study was potentially flawed with selection bias and risks for confounding factors. Secondly, for a lack of further follow-up, we failed to detect the progression of individuals either obese or not for further obtaining a stronger evidence for the causal relationship between obesity and myocardial injury, cardiac remodeling or even impaired cardiac function. Third, the relatively small sample size may threaten to testify the validity of our findings.

\section{Acknowledgements \\ All authors gratefully acknowledge the assistance of all staffs in cardiac ultra- sonography department and clinical laboratory department.}

\section{Authors' contributions}

$\mathrm{JH}$ wrote the main manuscript text. ML analyzed the data and drew the figures. ES collected the data. PY provided guidance on the idea of the article. JZ, $\mathrm{HJ}$ and JG revised the manuscript. And all authors reviewed the manuscript.

\section{Funding}

This work was jointly supported by the National Natural Science Foundation of China (Grant Nos. 81521001) and the Science and Research Fund of Shanghai Municipal Health Commission (CN) (20184Y0008).

\section{Availability of data and materials}

The datasets used and analyzed during the current study are available from the corresponding author on reasonable request.

\section{Declarations}

\section{Ethics approval and consent to participate}

The study was approved by Zhongshan Hospital Fudan University Ethics Committee, with the Approval No. being B2021-219. And all participants had signed informed consent, which was in line with the principles declared in the 1975 Declaration of Helsinki.

\section{Consent for publication}

All patients involved in the study have signed an informed consent form for the donation of biological specimens.

\section{Competing interests}

All authors declare that they have no competing interests.

\section{Author details}

${ }^{1}$ Department of General Practice, Zhongshan Hospital, Shanghai Medical College of Fudan University, Shanghai, China. ${ }^{2}$ Department of Health Management Center, Zhongshan Hospital, Shanghai Medical College of Fudan University, Shanghai, China. ${ }^{3}$ Shanghai Institute of Cardiovascular Diseases, Shanghai Institute of Clinical Bioinformatics, Zhongshan Hospital, Shanghai Medical College of Fudan University, Shanghai, China. ${ }^{4}$ Department of Endocrinology and Metabolism, Zhongshan Hospital, Shanghai Medical College of Fudan University, Shanghai, China.

Received: 8 September 2021 Accepted: 21 December 2021

Published online: 28 December 2021

\section{References}

1. Ortega FB, Lavie CJ, Blair SN. Obesity and cardiovascular disease. Circ Res. 2016;118(11):1752-70. 
2. Koliaki C, Liatis S, Kokkinos A. Obesity and cardiovascular disease: revisiting an old relationship. Metabolism. 2019;92:98-107.

3. Zhang L, Wei TT, Li Y, Li J, Fan Y, Huang FQ, Cai YY, Ma G, Liu JF, Chen QQ, Wang SL, Li H, Alolga RN, Liu B, Zhao DS, Shen JH, Wang XM, Zhu W, Li P, Qi LW. Functional metabolomics characterizes a key role for $\mathrm{N}$-acetylneuraminic acid in coronary artery diseases. Circulation. 2018;137(13):1374-90.

4. Alpert MA, Omran J, Bostick BP. Effects of obesity on cardiovascular hemodynamics, cardiac morphology, and ventricular function. Curr Obes Rep. 2016;5(4):424-34.

5. Blomstrand P, Sjöblom P, Nilsson M, et al. Overweight and obesity impair left ventricular systolic function as measured by left ventricular ejection fraction and global longitudinal strain. Cardiovascular Diabetology, 2018, 17(1): 113.

6. Kenchaiah S, Evans JC, Levy D, et al. Obesity and the risk of heart failure. $N$ Engl J Med. 2002;347(5):305-13.

7. Vasim I, Ahmad MI, Mongraw-Chaffin M, Soliman EZ. Association of obesity phenotypes with electrocardiographic subclinical myocardial injury in the general population. Clin Cardiol. 2019;42(3):373-8.

8. Eggers KM, Lindahl B. Application of cardiac troponin in cardiovascular diseases other than acute coronary syndrome. Clin Chem. 2017:63(1):223-35.

9. McEvoy JW, Chen Y, Rawlings A, Hoogeveen RC, Ballantyne CM, Blumenthal RS, Coresh J, Selvin E. Diastolic blood pressure, subclinical myocardial damage, and cardiac events: implications for blood pressure control. J Am Coll Cardiol. 2016;68(16):1713-22.

10. Tang O, Daya N, Matsushita K, Coresh J, Sharrett AR, Hoogeveen R, Jia X, Windham BG, Ballantyne C, Selvin E. Performance of high-sensitivity cardiac troponin assays to reflect comorbidity burden and improve mortality risk stratification in older adults with diabetes. Diabetes Care. 2020:43(6):1200-8.

11. Agewall S, Giannitsis E, Jernberg T, Katus H. Troponin elevation in coronary vs non-coronary disease. Eur Heart J. 2011:32(4):404-411.

12. Sugiura T, Dohi Y, Takase H, Yamashita S, Mizoguchi T, Fujii S, Ohte N. Close association between circulating high-sensitivity cardiac troponin I and metabolic syndrome in the general population. Hypertens Res. 2019:42(11):1768-75.

13. Luo D, Wan X, Liu J, Tong T. Optimally estimating the sample mean from the sample size, median, mid-range, and/or mid-quartile range. Stat Methods Med Res. 2018;27(6):1785-805.

14. Chen CM. Overview of obesity in Mainland China. Obes Rev. 2008;9(Suppl 1):14-21.

15. Gottdiener JS, Bednarz J, Devereux R, Gardin J, Klein A, Manning WJ, Morehead A, Kitzman D, Oh J, Quinones M, Schiller NB, Stein JH, Weissman NJ; American Society of Echocardiography. American Society of Echocardiography recommendations for use of echocardiography in clinical trials. J Am Soc Echocardiogr. 2004;17(10):1086-119.

16. Ndumele CE, Coresh J, Lazo M, Hoogeveen RC, Blumenthal RS, Folsom AR, Selvin E, Ballantyne CM, Nambi V. Obesity, subclinical myocardial injury, and incident heart failure. JACC Heart Fail. 2014;2(6):600-7.

17. Paulus WJ, Tschöpe C. A novel paradigm for heart failure with preserved ejection fraction: comorbidities drive myocardial dysfunction and remodeling through coronary microvascular endothelial inflammation. J Am Coll Cardiol. 2013;62(4):263-71.

18. Marchio P, Guerra-Ojeda S, Vila JM, Aldasoro M, Victor VM, Mauricio MD. Targeting early atherosclerosis: a focus on oxidative stress and inflammation. Oxid Med Cell Longev. 2019;1 (2019):8563845.

19. Anthony SR, Guarnieri AR, Gozdiff A, Helsley RN, Phillip Owens A, Tranter M. Mechanisms linking adipose tissue inflammation to cardiac hypertrophy and fibrosis. Clin Sci (Lond). 2019;133(22):2329-44.

20. Karmazyn M, Purdham DM, Rajapurohitam V, Zeidan A. Signalling mechanisms underlying the metabolic and other effects of adipokines on the heart. Cardiovasc Res. 2008;79(2):279-86.

21. Alpert MA, Lavie CJ, Agrawal H, Aggarwal KB, Kumar SA. Obesity and heart failure: epidemiology, pathophysiology, clinical manifestations, and management. TransI Res. 2014;164(4):345-56.

22. Olefsky JM, Glass CK. Macrophages, inflammation, and insulin resistance. Annu Rev Physiol. 2010;72:219-46.

23. Reilly SM, Saltiel AR. Adapting to obesity with adipose tissue inflammation. Nat Rev Endocrinol. 2017;13(11):633-43.
24. Boudina S, Sena S, O'Neill BT, Tathireddy P, Young ME, Abel ED. Reduced mitochondrial oxidative capacity and increased mitochondrial uncoupling impair myocardial energetics in obesity. Circulation. 2005;112(17):2686-95.

25. Lopaschuk GD, Folmes CD, Stanley WC. Cardiac energy metabolism in obesity. Circ Res. 2007;101(4):335-47.

26. Abel ED, O'Shea KM, Ramasamy R. Insulin resistance: metabolic mechanisms and consequences in the heart. Arterioscler Thromb Vasc Biol. 2012;32(9):2068-76.

27. Aimo A, Gaggin HK, Barison A, Emdin M, Januzzi JL Jr. Imaging, biomarker and clinical predictors of cardiac remodeling in heart failure with reduced ejection fraction. JACC Heart Fail. 2019;7(9):782-94.

28. Ravassa S, Kuznetsova T, Varo N, Thijs L, Delles C, Dominiczak A, Díez J, Staessen JA. Biomarkers of cardiomyocyte injury and stress identify left atrial and left ventricular remodelling and dysfunction: A populationbased study. Int J Cardiol. 2015;15(185):177-85.

29. Cooper LT Jr. Myocarditis. N Engl J Med. 2009;360(15):1526-38.

30. Spallarossa P, Tini G, Sarocchi M, Arboscello E, Grossi F, Queirolo P, Zoppoli G, Ameri P. Identification and management of immune checkpoint inhibitor-related myocarditis: use troponin wisely. J Clin Oncol. 2019;37(25):2201-2205

31. Bozkurt B, Aguilar D, Deswal A, Dunbar SB, Francis GS, Horwich T, Jessup M, Kosiborod M, Pritchett AM, Ramasubbu K, Rosendorff C, Yancy C; American Heart Association Heart Failure and Transplantation Committee of the Council on Clinical Cardiology; Council on Cardiovascular Surgery and Anesthesia; Council on Cardiovascular and Stroke Nursing; Council on Hypertension; and Council on Quality and Outcomes Research. Contributory Risk and Management of Comorbidities of Hypertension, Obesity, Diabetes Mellitus, Hyperlipidemia, and Metabolic Syndrome in Chronic Heart Failure: A Scientific Statement From the American Heart Association. Circulation. 2016;134(23): e535-e578.

32. Kenchaiah S, Evans JC, Levy D, Wilson PW, Benjamin EJ, Larson MG, Kannel WB, Vasan RS. Obesity and the risk of heart failure. N Engl J Med. 2002;347(5):305-13.

33. Chandramouli C, Tay WT, Bamadhaj NS, Tromp J, Teng TK, Yap JJL, MacDonald MR, Hung CL, Streng K, Naik A, Wander GS, Sawhney J, Ling LH, Richards AM, Anand I, Voors AA, Lam CSP; ASIAN-HF Investigators. Association of obesity with heart failure outcomes in 11 Asian regions: a cohort study. PLoS Med. 2019 Sep 24;16(9): e1002916.

34. Park SK, Ryoo JH, Oh CM, Choi JM, Kang JG, Lee JH, Chung JY, Jung JY. Effect of overweight and obesity (defined by asian-specific cutoff criteria) on left ventricular diastolic function and structure in a 29. General Korean Population Circ J. 2016;80(12):2489-95.

\section{Publisher's Note}

Springer Nature remains neutral with regard to jurisdictional claims in published maps and institutional affiliations.

Ready to submit your research? Choose BMC and benefit from:

- fast, convenient online submission

- thorough peer review by experienced researchers in your field

- rapid publication on acceptance

- support for research data, including large and complex data types

- gold Open Access which fosters wider collaboration and increased citations

- maximum visibility for your research: over 100M website views per year

At BMC, research is always in progress.

Learn more biomedcentral.com/submissions 